\title{
TMS-36 Varlıklarda Değer Düşüklüğü Standardına Göre Kullanım Değerinin Hesaplanması
}

\author{
Abdulkadir BİLEN* \\ Fatih ÖZKAN **
}

\section{ÖZET}

Ülkeler; sosyal, ekonomik, kültürel vb. yönlerden, birbirleriyle her geçen gün daha fazla ilişkili hale gelmekteler. Ülkeler arası artarak devam eden ilişkilerin, daha sağlıklı bir şekilde yürütülebilmesi için tüm dünyada çeşitli düzenlemeler yapılmaktadır. Kamu Gözetimi Muhasebe ve Denetim Standartlarl Kurumu tarafindan, uluslararasi ortak bir muhasebe dilinin tesis edilmesine yönelik, ülkemizde atılan adımlar bu kapsamda değerlendirilebilir. Bu çalışmanın amacı; teknoloji, küreselleşme, inovasyon ve rekabet gibi ekonomik hayatta belirleyici olan bazı unsurlarda yaşanan hızlı değişimin de etkisiyle, değeri düşen varlıklar konusunu düzenleyen TMS-36' nın incelenerek standartta açıklanan; "Kullanım Değeri" kavramının anlaşılmasına katkı sağlamaktır. Çalışmanın son bölümünde, Kullanım değerinin hesaplanmasına yönelik çeşitli senaryolar üzerinden örnek çözümler yapılmıştır.

Anahtar Kelimeler: TMS-36, Kullanım Değeri, Varlıklarda Değer Düşüklüğü

Jel Sinıflandırması: M41, M48

Calculation of Value in Use According to Turkish Accounting Standarts-36 on Impairment of Assets

\section{ABSTRACT}

Countries are becoming more and more associated with each other from social, economical, and cultural perspectives. To maintain the relations between countries in a more vigorous manner, a variety of regulations is made around the globe. In this context, the Public Oversight Accounting and Auditing Standards Authority of Turkey has taken steps to make Turkey's accounting language compatible with the rest of the world. Turkish Accounting Standart-36 regulates the issue of 'impairment of assets' which is affected by transformative and rapid changes in technology, globalization, innovation and competition and has a great impact on financial life. The aim of this study is to examine the TAS-36 and, thereby, to contribute to the understanding of "the value in use" concept described in the standards. In the last section of the study, Value in Use calculation has been illustrated for different scenarios.

Key Words: TAS 36, Value in Use, Impairment of Assets

Jel Classification: M41, M48

\footnotetext{
* Prof. Dr. Abdulkadir Bilen, Dicle Üniversitesi, İIBF İşletme Bölümü, abilen@dicle.edu.tr

** Öğr. Gör. Fatih Özkan, Mardin Artuklu Üniversitesi, Ömerli MYO, fatihozkan@artuklu.edu.tr
} 


\section{GíRiş}

Günümüzde küreselleşmenin bir sonucu olarak, bir işletmeye hissedar olmak veya o işletmeyi satın almak gibi faaliyetlerin, ülke sınırlarını aşarak uluslararası boyutta da çok sık görülmeye başlanması, işletmelerin uluslararası karşılaştırılabilirliğinin sağlanmasını zorunlu hale getirmiştir. Muhasebe standartları ile tesis edilmeye çalışılan ortak bir dil oluşturma çabası bu amacı gerçekleştirmeye yöneliktir. Bununla birlikte işletmelerin defter değerinin, gerçeğe uygun değeri ile takip edilebilmesi de muhasebe standartlarının üzerinde durduğu bir diğer önemli konudur.

Tarafların birbiriyle mal veya hizmet alış verişi yapmalarının ötesinde; birbirlerine hissedar olması, çeşitli şekillerde ortaklık kurması veya birbirlerini satın alması gibi daha kapsamlı faaliyetlerde de bulunmaları, finansal tabloların hazırlanması için gereken, güvenilir bilgiye olan ihtiyacı hızla artırmaktadır.

Tekdüzen Muhasebe Sisteminden, Muhasebe Standartlarına geçiş ile birlikte, ülkemizdeki muhasebe anlayışında da bir dönüşüm yaşanmaktadır. Türkiye Muhasebe Standartları; düzenlenecek finansal tablo sayısının artması, ölçme ve değerlemede farklı alternatifler sunulması, piyasa değeri kavramının daha önemli hale gelmesi, dipnotlarda tam açıklama ile daha şeffaf bir raporlama sunulması, duran varlıklarda değer düşüklüğü karşılığı ayrılması gibi birçok yenilik getirmiştir. Ancak en önemli yeniliğin, verginin tespitine odaklanmış bir muhasebe anlayışının yerine, işletmenin gerçek durumunun yansıtılmasını amaç edinmiş bir muhasebe anlayışının gelmesi olduğu söylenebilir.

Teknoloji, küreselleşme, inovasyon ve rekabet gibi ekonomik hayatta belirleyici olan temel unsurlarda yaşanan hızlı değişim, varlıklardan elde etmeyi beklediğimiz faydayı azaltabilmekte, bunun sonucunda varlıklarda değer düşüklüğü gözlenebilmektedir. Varlıkların değer düşüklüğü konusunu açıklayan standart olan TMS-36; değer düşüklügüunün fark edilmesi, hesaplanması, muhasebeleştirilmesi ve dipnotlarda açıllanması gibi konulara yönelik düzenlemeler getirmektedir.

Ülkemizde 1994 yılında uygulanmaya başlayan Tekdüzen Muhasebe sisteminde, "varlıklarda değer düşüklüğü" ile ilgili bir düzenleme yer almamaktadır. Vergi Usul Kanunu'nda yer alan olağanüstü amortisman uygulaması, bazı yönleriyle TMS-36' daki varlıklarda değer düşüklüğü uygulamasına benzese de, mahiyeti itibariye birbirinden oldukça farklıdır. Olağanüstü amortisman, duran varlığın herhangi bir nedenle beklenenden daha fazla değer kaybetmesi halinde, ancak Maliye bakanlığının belirlediği usul ve esaslara göre uygulanabilmektedir. Oysa TMS-36' ya göre, varlıklarda değer düşüklüğü belirtileri ortaya çıktığında, yapılan değer düşüklüğü testleri sonucunda, değer düşüklüğü tespit edilen varlığa karşılık ayrılabilmektedir. Marşap (2008: 140), maddi duran varlıklar açısından, standardın getirdiği en önemli yeniliğin, maddi duran varlıkların değer düşüklüğü testine tabi tutulması olduğunu ifade etmektedir. 


\section{VARLIKLARDA DEĞER DÜŞÜKLÜĞÜ}

Geri kazanılabilir tutar, bir varlığın veya nakit yaratan birimin, satış maliyetleri düşülmüş gerçeğe uygun değeri ile kullanım değerinden yüksek olanıdır. Defter değeri ise bir varlığın birikmiş amortisman (itfa) ve birikmiş değer düşüklüğü zararları indirildikten sonra finansal tablolara yansıtıldığı tutarıdır (TMS 36: Madde 6). Farklı sebeplerden dolayı varlıktan sağlanan faydanın azalması sonucu, varlığın geri kazanılabilir tutarı, defter değerinin altına düşebilmektedir. Varlıkta meydana gelen değer düşüklüğ̈̈; devletin aldığı ekonomik kararlar, rekabet şartlarındaki değişmeler, teknolojik gelişmeler gibi dış etkenlerden kaynaklanabildiği gibi, varlığın fonksiyonunu kaybetmesi ve varlıkta hasar meydana gelmesi gibi iç etkenlerden de kaynaklanabilmektedir.

TMS-36 Varlıklarda Değer Düşüklüğü Standard1, varlıkların defter değerinin, geri kazanılabilir tutarından daha yüksek bir değerle takip edilmesini önleyerek, varlıkların değer düşüklüğüne uğradığı durumlarda yapılması gereken işlemleri açıklamaktadır. Varlığın defter değerinin; kullanımı ya da satışı ile geri kazanılacak tutarından fazla olması durumunda, varlık değer düşüklüğüne uğramıştır ve işletmenin, değer düşüklüğü zararını muhasebeleştirmesi gerekir. Bunun yanında standart değer düşüklüğü zararının ne zaman iptal edilmesi gerektiğini ve kamuoyuna yapılması gereken açıklamaları da düzenlemektedir.

Bir varlığın geri kazanılabilir tutarının, defter değerinin altına düşmesi durumunda, ilgili varlık değer düşüklügüne uğramıştır (TMS 36: Madde 8). Değer düşüklüğü zararı, bir varlığın veya nakit yaratan birimin defter değerinin geri kazanılabilir tutarı aşan kısmını ifade eder (TMS 36: Madde 6).

Yeniden değerleme yöntemi, Tekdüzen Muhasebe Sisteminde enflasyon düzeltmesi gibi ihtiyaç duyulan durumlarda kullanılmaktaydı. Yeniden değerleme yöntemi, Muhasebe Standartlarında, "gerçeğe uygun değer" anlayışına verilen önemden dolayı, kullanımı çok daha yaygın bir değerleme modeli konumundadır. Örten ve Bayırlı (2007:37), standartta yeniden değerleme modeli olarak ifade edilen yöntemin özünün, "gerçeğe uygun değer" veya "makul değer" yöntemi olduğunu ifade etmektedir.

Gerçeğe uygun değer, piyasa katılımcıları arasında ölçüm tarihinde olağan bir işlemde, bir varlığın satışından elde edilecek veya bir borcun devrinde ödenecek fiyattır (TMS 36: Madde 6). Vinals (2008:123), gerçeğe uygun değerin özellikle yatırımcılara güvenilir bilgi vermesinin önemine vurgu yaparken, gerçeğe uygun değeri tespit edilecek varlığın aktif bir piyasası olmadığı durumlarda, bu avantajın kaybedileceğini ifade etmektedir.

İşletme, her bir raporlama dönemi sonunda, varlıkların değer düşüklüğüne uğramış olabileceğini gösteren herhangi bir belirtinin bulunup bulunmadığını değerlendirir (TMS 36: Madde 9).

Varlığın değer düşüklüğüne uğramış olabileceğine dair göstergeler aşağıdaki gibidir (TMS 36: Madde 12). 


\begin{tabular}{|c|c|}
\hline & $\begin{array}{c}\text { İŞLETME İÇİ BİLGİ } \\
\text { KAYNAKLARI }\end{array}$ \\
\hline $\begin{array}{l}\text { - Dönem içinde varlığın gerçeğe uygun } \\
\text { değerinin, zamanın ilerlemesinden veya normal } \\
\text { kullanımdan kaynaklanması beklenenden çok daha } \\
\text { fazla azalmış olduğuna dair gözlemlenebilir } \\
\text { göstergeler vardır. } \\
\text { - İşletmenin faaliyette bulunduğu teknolojik, } \\
\text { ekonomik veya hukuki çevre ile pazarda veya varlığın } \\
\text { tahsis edildiği piyasada işletme üzerinde olumsuz } \\
\text { etkisi olan önemli değişiklikler dönem içerisinde } \\
\text { gerçekleşmiş veya bu değişikliklerin yakın gelecekte } \\
\text { gerçekleşmesi beklenmektedir. } \\
\text { - Dönem içerisinde, faiz oranları veya diğer } \\
\text { yatırım kârlılığı ile ilgili piyasa oranları artmış olup; } \\
\text { söz konusu artışların, varlığın kullanım değerinin } \\
\text { hesaplanmasında kullanılan iskonto oranını önemli } \\
\text { ölçüde etkilemesi ve varlığın geri kazanılabilir tutarını } \\
\text { büyük ölçüde azaltması muhtemeldir. } \\
\text { İşletmenin net varlıklarının defter değeri piyasa } \\
\text { değerlerinden daha yüksektir. }\end{array}$ & $\begin{array}{l}\text { - Varlığın fiziksel hasara uğradığı } \\
\text { veya değer yitirdiğine ilişkin kanıt } \\
\text { bulunmaktadır. } \\
\text { - İşletmede, varlığın mevcut veya } \\
\text { gelecek kullanım yöntemini etkileyecek, } \\
\text { önemli olumsuz değişiklikler meydana } \\
\text { gelmiş veya bunların yakın gelecekte } \\
\text { meydana gelmesi beklenmektedir. Bu } \\
\text { değişiklikler şunları içerir; varlık kullanım } \\
\text { dışıdır; varlığın dahil olduğu faaliyetin sona } \\
\text { erdirilmesi veya yeniden yapılandırılması } \\
\text { planları vardır; varlığın beklenen tarihten } \\
\text { önce elden çıkarılması planlanmaktadır; } \\
\text { varlığın yararlı ömrünün sınırsız değil sınırlı } \\
\text { olduğu sonucuna varılmıştır. } \\
\text { İşletme içi raporlamada, varlığın ekonomik } \\
\text { performansının beklenenden daha kötü } \\
\text { olduğu veya olacağına ilişkin kanıt } \\
\text { mevcuttur. }\end{array}$ \\
\hline
\end{tabular}

İşletme yukarıda sayılanların dışında, varlığın değer düşüklüğüne uğramış olabileceğini gösteren başka belirtiler de tespit ederse, varlıkları için değer düşüklüğü testi uygulayabilir. Şerefiye gibi maddi olmayan duran varlıklar için de, standartta belirtilen şartlar sağlandığında, değer düşüklüğü testi uygulanır.

TMS-36; stoklara, inşaat sözleşmelerinden kaynaklanan varlıklara, ertelenmiş vergi varlıklarına, çalışanlara sağlanan faydalardan kaynaklanan varlıklara veya satış amaçlı elde tutulan olarak sınıflandırılmış varlıklara uygulanmaz (TMS36: Madde 3). Çünkü bahsedilen varlıklar için düzenlenen mevcut standartlar, ilgili varlıkların muhasebeleştirme ve ölçme kurallarını da içerir.

\section{TMS-36 KULLANIM DEĞERİ HESAPLAMA İLKELERİ}

Kullanım değeri TMS-36' da; "Bir varlıktan veya nakit yaratan birimden elde edilmesi beklenen gelecekteki nakit akışlarının bugünkü değeridir” şeklinde tanımlanmıştır (TMS 36: Madde 6). Kullanım değerinin tahmini için, varlığın kullanımı süresince ve varlığın kullanımı sonunda elden çıkarılmasından beklenen nakit giriş ve çıkışlarının tahmininin yapılması ve söz konusu gelecekteki nakit akışlarına uygun 1skonto oranının uygulanması şeklinde bir yol izlenmesi gerekmektedir (TMS 36: Madde 31). 
Varlığın elden çıkarılması için katlanılması gereken maliyetlerde, kullanım değerinin hesaplanmasında göz ardı edilmemesi gereken unsurlardandır. Elden çıkarma maliyetleri, finansman maliyetleri ve gelir vergisi gideri hariç, doğrudan bir varlığın veya nakit yaratan birimin elden çıkarılması ile ilgili maliyetlerdir (TMS 36: Madde 6).

Varlığın elden çıkarma maliyetlerine örnek olarak; yasal maliyetler, damga vergisi ve benzeri işlem vergileri, varlığın taşınma maliyetleri ile varlığı satışa hazır hale getirmek için oluşan ilave maliyetler gösterilebilir. Ancak, işten çıkarma ve varlığın elden çıkarılmasını müteakip, bir faaliyetin azaltılması ya da yeniden yapılandırılmasına ilişkin maliyetler, varlığın elden çıkarılması ile doğrudan ilgili ek maliyetler değildir. (TMS 36: Madde 28).

Kullanım değeri ölçülürken aşağıdaki işlemler uygulanır (TMS 36: Madde 33):

- İşletme, en iyi tahminleri mantıklı ve desteklenebilir varsayımlara dayandırır. İşletme dışı kanıtlara daha fazla ağırlık verir.

- Nakit akış projeksiyonlarını, yönetim tarafından onaylanan en güncel finansal bütçelere/tahminlere dayandırır; ancak gelecekte gerçekleştirilecek yeniden yapılandırmalardan veya varlı̆̆ın gelecekteki performansını artırma veya iyileştirme çalışmalarından kaynaklanan nakit giriş ya da çıkışlarını dikkate almaz. Bu bütçeleri/tahminleri esas alan projeksiyonlar, daha uzun bir dönemin kullanılması gerektiğine ilişkin haklı gerekçeler bulunmadığı sürece, en fazla 5 yıllık dönemi kapsar.

- $\quad$ İşletme için öngörülen büyüme oranı, daha yüksek bir oranın kullanılması gerektiğine ilişkin haklı gerekçeler bulunmadığı sürece, işletmenin faaliyet gösterdiği ürünler, endüstriler, ülke veya ülkeler ya da varlığın kullanıldığı piyasalar için geçerli uzun vadeli ortalama büyüme oranlarını aşmaz.

Gelecekteki nakit akışlarına ilişkin olarak 5 yıldan uzun dönemler için detaylı, kesin ve güvenilir finansal bütçeler/tahminler genellikle mevcut olmaz. Bu nedenle, yönetimin gelecekteki nakit akış tahminleri, en fazla 5 yıllık bir döneme ilişkin en güncel bütçeleri/tahminleri esas alır. Yönetimin, söz konusu projeksiyonların güvenilir olduğundan emin olması ve geçmiş deneyimler dikkate alındığında daha uzun dönemler için gelecekteki nakit akışlarını doğru olarak tahmin edebildiğini kanıtlaması durumunda, 5 yıldan daha uzun dönem için yapılan finansal bütçeleri/tahminlerinde yer alan nakit akışlarını esas alabilir (TMS 36: Madde 35).

İskonto oranı, paranın zaman değeri ve gelecekteki nakit akış tahminlerinde dikkate alınmamış olan, varlığa özgü risklere ilişkin cari piyasa değerlendirmesini yansıtan vergi öncesi oran olacaktır (TMS 36: Madde 55). 


\section{UYGULAMA ${ }^{1}$}

A işletmesinin varlıkları arasında; triko üretiminde kullandığı 4 adet makine ile 1 adet desen bilgisayarı bulunmaktadır. Varlıkların defter değerleri aşağıda gösterilmiştir.

\begin{tabular}{|l|c|c|c|}
\hline Varlıklar & Defter Değeri & Birik. Amortisman & Net Defter Değeri \\
\hline A makinesi & $350.000 \mathrm{TL}$ & $210.000 \mathrm{TL}$ & $140.000 \mathrm{TL}$ \\
\hline B makinesi & $250.000 \mathrm{TL}$ & $150.000 \mathrm{TL}$ & $100.000 \mathrm{TL}$ \\
\hline C makinesi & $200.000 \mathrm{TL}$ & $120.000 \mathrm{TL}$ & $80.000 \mathrm{TL}$ \\
\hline D makinesi & $200.000 \mathrm{TL}$ & $120.000 \mathrm{TL}$ & $80.000 \mathrm{TL}$ \\
\hline Desen Bilgisayarı & $75.000 \mathrm{TL}$ & $45.000 \mathrm{TL}$ & $30.000 \mathrm{TL}$ \\
\hline
\end{tabular}

Suriye de faaliyet gösteren triko imalat firmalarının önemli bir kısmı, ülkede yaşanan ekonomik kriz sebebiyle triko üretiminde kullandıkları makineleri, ülkemize getirerek satışa sunmuşlardır. $\mathrm{Bu}$ sebeple ikinci el triko makinesi fiyatlarında önemli ölçüde düşüş gözlenmiştir. A işletmesi, makine fiyatlarındaki bu düşüşten dolayı triko makinelerini ve desen bilgisayarını değer düşüklüğü testine tabi tutarak, söz konusu varlıkların geri kazanılabilir tutarını hesaplamak istemektedir.

\subsection{Her Bir Varlığın Ayrı Bir Nakit Üreten Birim Olduğu Varsayımına Göre Çözüm}

Nakit yaratan birim, diğer varlıklardan veya varlık gruplarından sağlanan nakit girişlerinden büyük ölçüde bağımsız bir nakit girişi yaratan belirlenebilir en küçük varlık grubudur (TMS 36: Madde 6).

a) Net Gerçeğe Uygun Değer

\begin{tabular}{|l|c|c|c|}
\hline Varlıklar & $\begin{array}{c}\text { Gerçeğe Uygun } \\
\text { Değer }\end{array}$ & $\begin{array}{c}\text { Satışa Hazırlık } \\
\text { Maliyeti } *\end{array}$ & $\begin{array}{c}\text { Net Gerçeğe } \\
\text { Uygun Değer** }\end{array}$ \\
\hline A makinesi & $84.000 \mathrm{TL}$ & $3.000 \mathrm{TL}$ & $81.000 \mathrm{TL}$ \\
\hline B makinesi & $60.000 \mathrm{TL}$ & $3.000 \mathrm{TL}$ & $57.000 \mathrm{TL}$ \\
\hline C makinesi & $48.000 \mathrm{TL}$ & $2.500 \mathrm{TL}$ & $45.500 \mathrm{TL}$ \\
\hline D makinesi & $48.000 \mathrm{TL}$ & $2.500 \mathrm{TL}$ & $45.500 \mathrm{TL}$ \\
\hline Desen Bilgisayarı & $25.000 \mathrm{TL}$ & $1.500 \mathrm{TL}$ & $23.500 \mathrm{TL}$ \\
\hline
\end{tabular}

* Makineleri satışa hazır hale getirmek için yapılması öngörülen; paketleme, yükleme vb. giderlerdir.

**Satış maliyetleri düşülmüş gerçeğe uygun değer

\footnotetext{
${ }^{1} \mathrm{Bu}$ başlık altındaki örneklerin çözümünde IFRS Foundation (2009)' dan yararlanılmıştır.
} 
b) Kullanım Değeri

\begin{tabular}{|l|c|c|c|c|c|c|}
\hline \multirow{2}{*}{ Makine } & \multicolumn{4}{|c|}{ Y1llara Göre Net Nakit Akışlar1* } & \multirow{2}{*}{$\begin{array}{c}\text { Hurda } \\
\text { Değeri }\end{array}$} & $\begin{array}{c}\text { Net Bugünkü } \\
\text { Değer ** }\end{array}$ \\
\cline { 2 - 5 } & 2015 & 2016 & 2017 & 2018 & & \\
\hline A Makinesi & $25.000 \mathrm{TL}$ & $25.750 \mathrm{TL}$ & $26.523 \mathrm{TL}$ & $27.318 \mathrm{TL}$ & $15.000 \mathrm{TL}$ & $96.567 \mathrm{TL}$ \\
\hline B Makinesi & $18.000 \mathrm{TL}$ & $18.540 \mathrm{TL}$ & $19.096 \mathrm{TL}$ & $19.669 \mathrm{TL}$ & $11.000 \mathrm{TL}$ & $69.665 \mathrm{TL}$ \\
\hline C Makinesi & $14.500 \mathrm{TL}$ & $14.935 \mathrm{TL}$ & $15.383 \mathrm{TL}$ & $15.845 \mathrm{TL}$ & $8.500 \mathrm{TL}$ & $55.873 \mathrm{TL}$ \\
\hline D Makinesi & $14.500 \mathrm{TL}$ & $14.935 \mathrm{TL}$ & $15.383 \mathrm{TL}$ & $15.845 \mathrm{TL}$ & $8.500 \mathrm{TL}$ & $55.873 \mathrm{TL}$ \\
\hline Desen Bil. & $6.000 \mathrm{TL}$ & $6.180 \mathrm{TL}$ & $6.365 \mathrm{TL}$ & $6.556 \mathrm{TL}$ & $1.000 \mathrm{TL}$ & $21.407 \mathrm{TL}$ \\
\hline
\end{tabular}

* Ülke ekonomisinin büyüme oranı olan \%3, nakit akışlarının yıllık artış oranı olarak kabul edilmiştir. ** Cari piyasa faiz oranı olan \%8, Net bugünkü değerin hesaplanmasında iskonto oranı olarak kabul edilmiştir.

c) Geri Kazanılabilir Tutar

\begin{tabular}{|l|c|c|c|c|c|}
\hline & A Makinesi & B Makinesi & C Makinesi & D Makinesi & $\begin{array}{c}\text { Desen } \\
\text { Bilgisayar1 }\end{array}$ \\
\hline Net Defter Değeri & $140.000 \mathrm{TL}$ & $100.000 \mathrm{TL}$ & $80.000 \mathrm{TL}$ & $80.000 \mathrm{TL}$ & $30.000 \mathrm{TL}$ \\
\hline Net Ger. Uy. Değer & $81.000 \mathrm{TL}$ & $57.000 \mathrm{TL}$ & $45.500 \mathrm{TL}$ & $45.500 \mathrm{TL}$ & $23.500 \mathrm{TL}$ \\
\hline Kullanım Değer & $96.567 \mathrm{TL}$ & $69.665 \mathrm{TL}$ & $55.873 \mathrm{TL}$ & $55.873 \mathrm{TL}$ & $21.407 \mathrm{TL}$ \\
\hline Geri Kaz.Tutar * & $96.567 \mathrm{TL}$ & $69.665 \mathrm{TL}$ & $55.873 \mathrm{TL}$ & $55.873 \mathrm{TL}$ & $23.500 \mathrm{TL}$ \\
\hline Değer Düşüklüğü & $43.433 \mathrm{TL}$ & $30.335 \mathrm{TL}$ & $24.127 \mathrm{TL}$ & $24.127 \mathrm{TL}$ & $6.500 \mathrm{TL}$ \\
\hline
\end{tabular}

* Net gerçeğe uygun değer ile kullanım değerinden yüksek olanı geri kazanılabilir tutar olarak belirlenmiştir.

\subsection{Makinelerin Her Birinin Ayrı Bir Nakit Üreten Birim; Desen Bilgisayarının, Makinelerin Sağladığı Nakit Akışına Yardımcı Bir Unsur Olduğu Varsayımına Göre Çözüm}

a) Net Gerçeğe Uygun Değer

\begin{tabular}{|l|c|c|c|}
\hline Varlıklar & $\begin{array}{c}\text { Gerçeğe Uygun } \\
\text { Değer }\end{array}$ & Satışa Hazırlık Maliyeti * & $\begin{array}{c}\text { Net Gerçeğe Uygun } \\
\text { Değer }\end{array}$ \\
\hline A Makinesi & $84.000 \mathrm{TL}$ & $3.000 \mathrm{TL}$ & $81.000 \mathrm{TL}$ \\
\hline B Makinesi & $60.000 \mathrm{TL}$ & $3.000 \mathrm{TL}$ & $57.000 \mathrm{TL}$ \\
\hline C Makinesi & $48.000 \mathrm{TL}$ & $2.500 \mathrm{TL}$ & $45.500 \mathrm{TL}$ \\
\hline D Makinesi & $48.000 \mathrm{TL}$ & $2.500 \mathrm{TL}$ & $45.500 \mathrm{TL}$ \\
\hline Desen Bilgisayarı & $* *$ & - & - \\
\hline
\end{tabular}

* Makineleri satışa hazır hale getirmek için yapılması öngörülen; paketleme, yükleme vb. giderlerdir.

** Diğer varlıklardan bağımsız satış bedeli, önemsenmeyecek düzeydedir. 
b) Kullanım Değeri

\begin{tabular}{|l|c|c|c|c|c|c|}
\hline \multirow{2}{*}{ Makine } & \multicolumn{4}{|c|}{ Yıllara Göre Net Nakit Akışları* } & \multirow{2}{*}{$\begin{array}{c}\text { Hurda } \\
\text { Değeri }\end{array}$} & $\begin{array}{c}\text { Net Bugünkü } \\
\text { Değer ** }\end{array}$ \\
\cline { 2 - 7 } & 2015 & 2016 & 2017 & 2018 & & \\
\hline A Makinesi & $25.000 \mathrm{TL}$ & $25.750 \mathrm{TL}$ & $26.523 \mathrm{TL}$ & $27.318 \mathrm{TL}$ & $15.000 \mathrm{TL}$ & $96.567 \mathrm{TL}$ \\
\hline B Makinesi & $18.000 \mathrm{TL}$ & $18.540 \mathrm{TL}$ & $19.096 \mathrm{TL}$ & $19.669 \mathrm{TL}$ & $11.000 \mathrm{TL}$ & $69.665 \mathrm{TL}$ \\
\hline C Makinesi & $14.500 \mathrm{TL}$ & $14.935 \mathrm{TL}$ & $15.383 \mathrm{TL}$ & $15.845 \mathrm{TL}$ & $8.500 \mathrm{TL}$ & $55.873 \mathrm{TL}$ \\
\hline D Makinesi & $14.500 \mathrm{TL}$ & $14.935 \mathrm{TL}$ & $15.383 \mathrm{TL}$ & $15.845 \mathrm{TL}$ & $8.500 \mathrm{TL}$ & $55.873 \mathrm{TL}$ \\
\hline Desen Bil.*** & - & - & - & - & $* * * *$ & - \\
\hline
\end{tabular}

* Ülke ekonomisinin büyüme oranı olan \%3, nakit akışlarındaki artış oranı olarak kabul edilmiştir.

** Cari piyasa faiz oranı olan \%8, Net bugünkü değerin hesaplanmasında iskonto oranı olarak kabul edilmiştir.

*** Nakit üretmeyen birim örneği Greunıng, Scott ve Terblanche (2010:293)’ ten türetilmiştir.

**** Hurda değeri önemsenmeyecek düzeydedir.

c) Desen bilgisayarının Makinelere dağıtımı*

\begin{tabular}{|l|c|c|c|c|}
\hline & $\begin{array}{c}\text { Desen Bil. } \\
\text { Dağıtım Anahtarı }\end{array}$ & Dağıtım Tutarı & $\begin{array}{c}\text { Dağıtım Öncesi } \\
\text { Defter Değeri }\end{array}$ & $\begin{array}{c}\text { Dağıtılmış Defter } \\
\text { Değeri }\end{array}$ \\
\hline A Makinesi & $\begin{array}{c}140.000 / 400.000 \\
\text { X 30.000 }\end{array}$ & $10.500 \mathrm{TL}$ & $140.000 \mathrm{TL}$ & $150.500 \mathrm{TL}$ \\
\hline B Makinesi & $\begin{array}{c}100.000 / 400.000 \\
\text { X 30.000 }\end{array}$ & $7.500 \mathrm{TL}$ & $100.000 \mathrm{TL}$ & $107.500 \mathrm{TL}$ \\
\hline C Makinesi & $\begin{array}{c}80.000 / 400.000 \\
\text { X 30.000 }\end{array}$ & $6.000 \mathrm{TL}$ & $80.000 \mathrm{TL}$ & $86.000 \mathrm{TL}$ \\
\hline D Makinesi & $\begin{array}{c}80.000 / 400.000 \\
\text { X 30.000 }\end{array}$ & $6.000 \mathrm{TL}$ & $80.000 \mathrm{TL}$ & $86.000 \mathrm{TL}$ \\
\hline
\end{tabular}

* Desen bilgisayarı, tek başına nakit üretmediği için kullanım değeri tespit edilememektedir.

d) Geri kazanılabilir Tutar

\begin{tabular}{|l|c|c|c|c|}
\hline & A Makinesi & B Makinesi & C Makinesi & D Makinesi \\
\hline Dağıtılmış Defter D. & $150.500 \mathrm{TL}$ & $107.500 \mathrm{TL}$ & $86.000 \mathrm{TL}$ & $86.000 \mathrm{TL}$ \\
\hline Net Gerçeğe Uygun Değer & $81.000 \mathrm{TL}$ & $57.000 \mathrm{TL}$ & $45.500 \mathrm{TL}$ & $45.500 \mathrm{TL}$ \\
\hline Kullanım Değer & $96.567 \mathrm{TL}$ & $69.665 \mathrm{TL}$ & $55.873 \mathrm{TL}$ & $55.873 \mathrm{TL}$ \\
\hline Geri Kazanılabilir Tutar* & $96.567 \mathrm{TL}$ & $69.665 \mathrm{TL}$ & $55.873 \mathrm{TL}$ & $55.873 \mathrm{TL}$ \\
\hline Değer Düşüklüğü & $53.933 \mathrm{TL}$ & $37.835 \mathrm{TL}$ & $30.127 \mathrm{TL}$ & $30.127 \mathrm{TL}$ \\
\hline
\end{tabular}

* Net gerçeğe uygun değer ile kullanım değerinden yüksek olanı geri kazanılabilir tutar olarak belirlenmiştir. 
e) Dağıtımı Yapılmış Değer Düşüklükleri*

\begin{tabular}{|l|c|c|c|c|}
\hline & A Makinesi & B Makinesi & C Makinesi & D Makinesi \\
\hline $\begin{array}{l}\text { Dağıtılmış Değer } \\
\text { Düşüklüğü }\end{array}$ & $53.933 \mathrm{TL}$ & $37.835 \mathrm{TL}$ & $30.127 \mathrm{TL}$ & $30.127 \mathrm{TL}$ \\
\hline $\begin{array}{l}\text { Desen Bil.Değer } \\
\text { Düşüklüğü Anah. }\end{array}$ & $\begin{array}{c}10.500 / 150.500 \\
\text { X 53.933 }\end{array}$ & $\begin{array}{c}7.500 / 107.500 \\
\text { X 37.835 }\end{array}$ & $\begin{array}{c}6.000 / 86.000 \\
\text { X 30.127 }\end{array}$ & $\begin{array}{c}6.000 / 86.000 \\
\text { X 30.127 }\end{array}$ \\
\hline $\begin{array}{l}\text { Desen Bil. Değer } \\
\text { Düşüklüğ̈̈** }\end{array}$ & $3.763 \mathrm{TL}$ & $2.640 \mathrm{TL}$ & $2.102 \mathrm{TL}$ & $2.102 \mathrm{TL}$ \\
\hline $\begin{array}{l}\text { Makineler Değer } \\
\text { Düşüklüğü Anah. }\end{array}$ & $\begin{array}{c}140.000 / 150.500 \\
\text { X 53.933 }\end{array}$ & $\begin{array}{c}100.000 / 107.500 \\
\text { X 37.835 }\end{array}$ & $\begin{array}{c}80.000 / 86.000 \\
\text { X 30.127 }\end{array}$ & $\begin{array}{c}80.000 / 86.000 \\
\text { X 30.127 }\end{array}$ \\
\hline $\begin{array}{l}\text { Makineler Değer } \\
\text { Düşüklüğü }\end{array}$ & $50.170 \mathrm{TL}$ & $35.195 \mathrm{TL}$ & $28.025 \mathrm{TL}$ & $28.025 \mathrm{TL}$ \\
\hline
\end{tabular}

* Tabloda uygulanan dağıtım anahtarı için Örten, Kaval ve Karapınar (2013:519)' dan yararlanılmıştır.

** Dağıtım yapıldıktan sonra desen bilgisayarı değer düşüklüğü toplamı: 10.607 TL

\subsection{Varlıkların Birbirini Tamamlayan Tek Bir Nakit Üreten Birim Olduğu Varsayımına Göre Çözüm}

a) Net Gerçeğe Uygun Değer

\begin{tabular}{|c|c|c|c|}
\hline Varlıklar & $\begin{array}{c}\text { Gerçeğe Uygun } \\
\text { Değer }\end{array}$ & Satışa Hazırlık Maliyeti * & $\begin{array}{c}\text { Net Gerçeğe Uygun } \\
\text { Değer }\end{array}$ \\
\hline 5 Varlık & $265.000 \mathrm{TL}$ & 12.500 & $252.500 \mathrm{TL}$ \\
\hline
\end{tabular}

* Makineleri satışa hazır hale getirmek için yapılması öngörülen; paketleme, yükleme vb. giderlerdir.

b) Kullanım Değeri

\begin{tabular}{|c|c|c|c|c|c|c|}
\hline \multirow{2}{*}{ YIL } & \multicolumn{3}{|c|}{ YILLARA GÖRE NET NAKIT AKIŞLARI * } & \multirow{2}{*}{$\begin{array}{c}\text { HURDA } \\
\text { DEGERİ }\end{array}$} & $\begin{array}{c}\text { NET } \\
\text { BUGÜNKÜ } \\
\text { DEGEGER ** }\end{array}$ \\
\cline { 2 - 6 } & 2015 & 2016 & 2017 & 2018 & & 299.385 TL \\
\hline
\end{tabular}

* Ülke ekonomisinin büyüme oranı olan \%3, nakit akışlarındaki artış oranı olarak kabul edilmiştir.

** Cari piyasa faiz oranı olan $\% 8$, Net bugünkü değerin hesaplanmasında iskonto oranı olarak kabul edilmiştir.

c) Geri Kazanılabilir Tutar

\begin{tabular}{|l|c|}
\hline & 5 Varlık \\
\hline Net Defter Değeri & 430.000 TL \\
\hline Net Gerçeğe Uygun Değer & 252.500 TL \\
\hline Kullanım Değer & 299.385 TL \\
\hline Geri Kazanılabilir Tutar * & 299.385 TL \\
\hline Değer Düşüklüğ̈ & 130.615 TL \\
\hline
\end{tabular}

* Net gerçeğe uygun değer ile kullanım değerinden yüksek olanı geri kazanılabilir tutar olarak belirlenmiştir. 
d) Değer Düşüklüğünün Varlıklara Dağıtımının Yapılması*

\begin{tabular}{|l|c|c|c|c|}
\hline & Defter Değeri & $\begin{array}{c}\text { Defter Değeri } \\
\text { Dağıtım Anah. }\end{array}$ & $\begin{array}{c}\text { Değer Düşüklüğü } \\
\text { Dağıımı }\end{array}$ & $\begin{array}{c}\text { Değer } \\
\text { Düşüklüğü }\end{array}$ \\
\hline A Makinesi & $140.000 \mathrm{TL}$ & $140.000 / 430.000$ & $130.615 \times 0,326$ & $42.526 \mathrm{TL}$ \\
\hline B Makinesi & $100.000 \mathrm{TL}$ & $100.000 / 430.000$ & $130.615 \times 0,233$ & $30.376 \mathrm{TL}$ \\
\hline C Makinesi & $80.000 \mathrm{TL}$ & $80.000 / 430.000$ & $130.615 \times 0,186$ & $24.300 \mathrm{TL}$ \\
\hline D Makinesi & $80.000 \mathrm{TL}$ & $80.000 / 430.000$ & $130.615 \times 0,186$ & $24.300 \mathrm{TL}$ \\
\hline Desen Bilgisayarı & $30.000 \mathrm{TL}$ & $30.000 / 430.000$ & $130.615 \times 0,070$ & $9.113 \mathrm{TL}$ \\
\hline TOPLAM & $430.000 \mathrm{TL}$ & $430.000 / 430.000$ & $130.615 \times 1$ & $130.615 \mathrm{TL}$ \\
\hline
\end{tabular}

* Dağıtım anahtarı için varlıkların net defter değeri baz alınmıştır.

\section{DEĞER DÜŞÜKLÜĞÜNÜN MUHASEBELEŞTİRILMESI}

Bir varlığın defter değerinin, o varlığın kullanımı ya da satışı ile geri kazanılacak tutarından fazla olması durumunda, varlık değer düşüklüğüne uğramıştır. Bu durumda değer düşüklüğü zararının muhasebeleştirilmesi gerekir (TMS 36: Madde 1).

Muhasebe kayıtları, tekrardan kaçınmak için tüm varlıkların birbirini tamamlayan bir tek nakit üreten birim sayıldığı 3. varsayıma göre yapılmıştır. Muhasebe kayıtlarında Örten, Kaval ve Karapınar (2013:517)'ın görüşlerinden yararlanılmıştır.

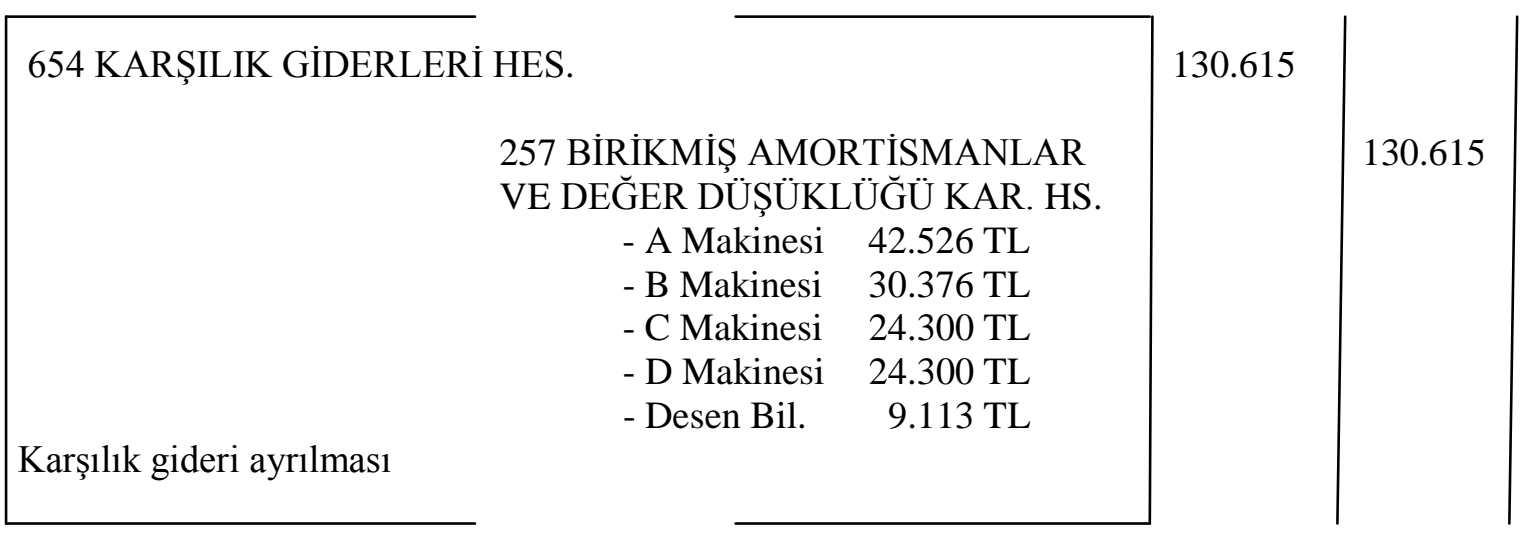

Akdoğan ve Sevilengül (2007:59), maddi duran varlıklardaki değer düşüklüklerini izlemek üzere, yeni bir hesap açmak için boş kod bulunmadığından, "257 Birikmiş Amortisman" hesabının adını "257 Birikmiş Amortismanlar ve Değer Düşüklüğü Karşılığı" olarak değiştirilmesini ve hesabın kapsamının genişletilerek değer düşüklüğü karşılık tutarlarının da bu hesapta izlenmesini önermektedir. Tek Düzen Hesap Planı'ndaki 25 Maddi Duran Varlıklar grubunda boş hesap bulunmadığı için bu görüş uygun görülebilir. Ancak, Birikmiş Amortismanlar Hesabı ile Değer Düşüklüğü Karşılığı Hesabının aynı hesapta toplanması, finansal raporlamanın tam açıklama ilkesine ters düşecek olması yönüyle 
eleştirilebilir. Bu sebeple söz konusu kalemlerin farklı hesaplarda takip edilmesi daha uygun olabilir.

Sağlam, Yolcu ve Eflatun (2014:413), alacaklı hesap olarak; Maddi Duran Varlıklar Değer Düşüklüğü Karşılıkları hesabını kullanmaktadır. Akbulut (2015:794), duran varlıklarda değer düşüklüğü yaşanması durumunda borçlu hesap olarak, Diğer Giderler Hesabını kullanırken, ilgili duran varlık hesabını alacaklandırmaktadır.

Değer düşüklüğü zararı, Vergi Usul Kanunu’na göre kanunen kabul edilmeyen gider statüsünde olduğu için kanunen kabul edilmeyen gider kaydının yapılması gerekir.

960 MATRAHA İLAVELER HES.

961 MATRAHA İLAVE KAR.HES.

Kanunen kabul edilmeyen giderlerin kaydı

Sağlam, Yolcu ve Eflatun (2014:413) borçlu hesap olarak; "900 Kanunen Kabul Edilmeyen Giderler" hesabını kullanırken, alacaklı hesap olarak; "903 Matraha Eklenecek Tutarlar" hesabını kullanmaktadır.

Ertelenmiş vergiler, varlığın değer düşüklüğünden sonraki yeni defter değeri ile değer düşüklüğü yapılmamış defter değeri (vergiye esas değeri) arasındaki fark üzerinden hesaplanır. Dolayısıyla değer düşüklüğü karşılığı ayrıldığında, ertelenmiş verginin de muhasebeleştirilmesi gerekir (Akgül, 2009:15).

284 ERTELENMISŞ VERGİ

VARLIĞI HES.

Değer düşüklüğünün vergi etkisi $(130.6125 \times 0.20)$
26.123

26.123

Sağlam, Yolcu ve Eflatun (2014:414) Alacaklı hesap olarak; Sürdürülen Faaliyetler Ertelenmiş Vergi Gelir Etkisi Hesabını kullanmaktadır. Akbulut (2015:610) ise Ertelenmiş Vergi Varlığı Hesabını borçlandırırken, Ertelenmiş Vergi Geliri Hesabını alacaklandırmaktadır.

\section{SONUÇ}

Türkiye Muhasebe Standartları ve Türkiye Finansal Raporlama Standartlarının ülkemizde uygulanmaya başlanması ile iki temel amacın gerçekleştirilmeye çalışıldığı söylenebilir. Birinci amaç; uluslararası piyasada ortak bir muhasebe dili oluşturarak, işletmelerin birbirleri ile karşılaştırılabilirliğini temin etmek ve uluslararası düzeydeki 
ekonomik ilişkilerin sorunsuz bir şekilde yürümesine katkı sağlamaktır. İkinci amaç ise; standartların geneline hakim olan "gerçeğe uygun değer" anlayışıyla, işletmelerin gerçek durumlarını finansal raporlara yansıtmaya çalışan, böylelikle işletmenin ilişkide olduğu taraflara doğru, güvenilir ve açıklayıcı bilgi veren bir muhasebe sisteminin tesis edilmesidir.

Türkiye Muhasebe Standartları, duran varlıklarda değer düşüklüğü uygulaması gibi, Tekdüzen Muhasebe Sisteminde olmayan bazı yeni uygulamalar getirmiştir. TMS ile gelen, duran varlıklarda değer düşüklüğü uygulaması, Tekdüzen Muhasebe Sisteminde yer alan, olağanüstü amortisman uygulamasından birçok yönüyle oldukça farklıdır. TMS' ye göre varlığın cari değeri, aktif piyasasının olup olmamasına göre iki farklı şekilde hesaplanmaktadır. Aktif piyasası olan duran varlıkların, "gerçeğe uygun değeri" kolayca bulunabilmektedir. Ancak söz konusu varlığın aktif piyasası yoksa veya aktif piyasası olmasına rağmen "kullanım değerinin", gerçeğe uygun değerinden yüksek olduğu yönünde belirtiler varsa, varlığın kullanım değerinin hesaplanması gerekmektedir.

Duran varlıkların kullanım değerinin hesaplanması, temelde bir takım tahminlere dayanmaktadır. Kullanım değeri hesaplanacak duran varlığın, gelecek yıllarda getireceği nakit akışları ve toplam nakit akışının bugünkü değere indirgenmesinde kullanılacak iskonto oranı, kullanıcıların yapması gereken tahminlere örnek verilebilir. Standartta, kullanım değerinin hesaplanması için bazı düzenlemeler mevcuttur, ancak kullanım değerinin hesaplanmasında temel belirleyici unsur, kullanıcıların yapacağı tahminlerdir. Kullanım değerinin hesaplanması konusu; gelecek yıllara ait yapılacak tahminlerin, isabetli olmayabileceği ve kişiden kişiye değişeceği için öznel sonuçlar doğurabileceği açısından eleştirilmektedir.

TMS' nin getirdiği yenilikler, Tekdüzen Hesap planında da bir takım değişikliklerin yapılmasını gerekli kılmaktadır. Örneğin duran varlıkların değer düşüklüğü için kullanılacak bir hesap oluşturulmalı veya mevcut hesaplardan birisi tayin edilerek, kullanıcılar arasında uygulama birliği sağlanmalıdır.

\section{KAYNAKLAR}

Akbulut, Akın (2015), "Karşılaştırmalı TMS/TFRS-Vergi Uygulamaları ve Sonuçları”, Maliye Hesap Uzmanları Derneği, Ankara.

Akdoğan, Nalan - Sevilengül, Orhan (2007), “Türkiye Muhasebe Standartlarına Uyum İçin Tekdüzen Hesap Planında Yapılması Gereken Değişiklikler”, Mali Çözüm, Sayı:84, Kasım-Aralık, ss.29-69.

Akgül, Ali İhsan (2009), "Türkiye Finansal Raporlama Standartları Açısından Varlıklarda Değer Düşüklüğü ve Şerefiyenin İncelenmesi”, Kocaeli Üniversitesi Sosyal Bilimler Enstitüsü Dergisi, Sayı:18, ss:1-34.

Greuning, Hennie - Scott, Darrel - Terblanche, Simonet (2010), “International Financial Reporting Standards A Practıcal Guıde”, The World Bank, Washington D.C. Erişim Tarihi:01.02.2015,.https://openknowledge.worldbank.org/bitstream/handle/10986/2288/6080 70PUB0Fina10Box358332B01PUBLIC1.pdf?sequence=1 
IFRS Foundation, (2009). Training Material for the IFRS for SMEs, Module 27-Impairment of Assets, s:1-72, Erişim Tarihi: 30.01.2015, http://www.ifrs.org/IFRS-forSMEs/Documents/IFRS\%20for\%20SMEs\%20Modules/Module\%2027_version2013-2.pdf

Marşap, Beyhan (2008), "Maddi Duran Varlıklarda Amortisman Uygulaması ve Yararlı Ömrün Belirlenmesi”, VI. Muhasebe Uygulamaları ve Vergi Mevzuatı Sempozyumu, Ankara Serbest Muhasebeci ve Mali Müşavirler Odas1, ss:1-258

Örten, Remzi - Bayırlı, Rıdvan (2007), “TMS 16'ya Göre Maddi Duran Varlıkların Dönem Sonunda Değerlemesi ve Muhasebe Uygulamaları”, Muhasebe ve Finansman Dergisi, Say1:Ekim, ss:34-50.

Örten, Remzi - Kaval, Hasan - Karapınar, Aydın (2013), “Türkiye Muhasebe-Finansal Raporlama Standartları Uygulama ve Yorumları”, Gazi Kitabevi, Ankara.

Sağlam, Necdet - Yolcu, Mehmet - Eflatun, Ali Osman (2014), “Örneklerle UFRS Kayıtları”, Özel Bask1, Ankara.

TMS 36, Varlıklarda Değer Düşüklüğü Standardı, 18.03.2006 Tarih ve 26112 Sayılı Resmi Gazete'de Yayımlanan 28 Sira No'lu Tebliğ.

Vinals, Jose (2008) “Improving Fair Value Accounting”, Financial Stability Review, Valuation and financial stability, Erişim Tarihi: 15.01.2015, https://www.banquefrance.fr/fileadmin/user_upload/banque_de_france/publications/Revue_de_la_stabilite_financi ere/etud13_1008.pdf 
